\title{
Events in 2022
}

\section{Announcement}

The Korean Council of Science Editors announces the schedule of the events in 2022. Precise schedule and registration of above workshops were or will be available from: https://www.kcse.org.

Table 1. Schedule of the events by the Korean Council of Science Editors in 2022

\begin{tabular}{|c|c|c|c|c|c|c|}
\hline & January & February & March & April & May & June \\
\hline Science Editing (twice a year) & & Vol.9 No.1 (20) & & & & \\
\hline Newsletter (4 times a year) & & & No. 41 (31) & & & No. 42 (30) \\
\hline \multicolumn{7}{|l|}{ International Conference } \\
\hline Editor's Workshop & $\begin{array}{c}2022 \text { Post- } \\
\text { conference } \\
\text { Workshop (22) }\end{array}$ & & & & & \\
\hline $\begin{array}{l}\text { Manuscript Editor's } \\
\text { Training \& Workshop }\end{array}$ & & & $\begin{array}{c}\text { Basic Manuscript } \\
\text { Editing } \\
(10,17,24,31)\end{array}$ & $\begin{array}{c}\text { Basic Manuscript } \\
\text { Editing } \\
(7,14,21,28)\end{array}$ & & \\
\hline \multirow[t]{2}{*}{ Publication Ethics Workshop } & & & & $\begin{array}{l}\text { Publication } \\
\text { Ethics Workshop } \\
\text { (22) }\end{array}$ & & \\
\hline & July & August & September & October & November & December \\
\hline Science Editing (twice a year) & & Vol.9 No.2 (20) & & & & \\
\hline Newsletter (4 times a year) & & & No. $43(30)$ & & & No. 44 (31) \\
\hline International Conference & $\begin{array}{l}\text { The 7th Asian } \\
\text { Science Editors' } \\
\text { Conference and } \\
\text { Workshop } 2022\end{array}$ & & & & & \\
\hline Editor's Workshop & $\begin{array}{l}\text { Scopus } \\
\text { Workshop } \\
\text { (20) }\end{array}$ & & & $\begin{array}{l}\text { Scopus } \\
\text { Workshop } \\
\text { (27-28) }\end{array}$ & $\begin{array}{l}\text { Editor's } \\
\text { Workshop (24) }\end{array}$ & \\
\hline $\begin{array}{l}\text { Manuscript Editor's } \\
\text { Training \& Workshop }\end{array}$ & $\begin{array}{l}\text { Examination for } \\
\text { Korea } \\
\text { Manuscript } \\
\text { Editors } \\
\text { Certification (15) }\end{array}$ & & & & $\begin{array}{l}\text { Manuscript } \\
\text { Editor's } \\
\text { Workshop (3) }\end{array}$ & \\
\hline Publication Ethics Workshop & $\begin{array}{c}\text { Publication } \\
\text { Ethics Workshop } \\
\text { (1) }\end{array}$ & & & & $\begin{array}{c}\text { Publication } \\
\text { Ethics Workshop } \\
\text { (25) }\end{array}$ & \\
\hline
\end{tabular}

